and $63 \%$ positive for anti-cyclic citrullinated peptide antibodies. Overall, $33.1 \%$ $(591 / 1776)$ of patients had an MTC. A markedly larger percentage of patients with high disease activity had MTC (range 55.1\%-43.5\%) compared to patients with moderate disease (range 38.7\%-27.8\%) (table 1). Sensitivity, specificity, predictive values, and accuracy at each DAM threshold level varied markedly by DAM, with RAPID3 having a higher sensitivity, lower specificity, and less accuracy than DAS28 or CDAI (table 2).

Abstract FRI0018 - Table 1. Rates of MTC Stratified by DAM

\begin{tabular}{|lccc|}
\hline & \multicolumn{3}{c|}{ Patients with MTC, n/N (\%) } \\
\cline { 2 - 4 } High & DAS28 & CDAl & RAPID3 \\
Moderate & $285 / 737(38.7 \%)$ & $219 / 601(36.4 \%)$ & $155 / 558(27.8 \%)$ \\
Low & $72 / 283(25.4 \%)$ & $105 / 547(19.2 \%)$ & $47 / 217(21.7 \%)$ \\
Remission & $69 / 443(15.6 \%)$ & $36 / 209(17.2 \%)$ & $43 / 206(20.9 \%)$ \\
n, number of patients with MTC; $N$, number of patients with level of disease severity.
\end{tabular}

Abstract FRI0018 - Table 2. Performance of DAMs for Prediction of MTC

\begin{tabular}{|c|c|c|c|c|}
\hline & & & itive Thres! & \\
\hline & & High & $\begin{array}{c}\text { High/ } \\
\text { Moderate }\end{array}$ & $\begin{array}{c}\text { High/ } \\
\text { Moderate/ } \\
\text { Low }\end{array}$ \\
\hline Sensitivity & $\begin{array}{l}\text { DAS28 } \\
\text { CDAl } \\
\text { RAPID3 }\end{array}$ & $\begin{array}{l}27.9 \% \\
39.1 \% \\
58.5 \%\end{array}$ & $\begin{array}{l}76.1 \% \\
76.1 \% \\
84.8 \%\end{array}$ & $\begin{array}{l}88.3 \% \\
94.9 \% \\
92.7 \%\end{array}$ \\
\hline Specificity & $\begin{array}{l}\text { DAS28 } \\
\text { CDAI } \\
\text { RAPID3 }\end{array}$ & $\begin{array}{l}87.5 \% \\
84.1 \% \\
62.1 \%\end{array}$ & $\begin{array}{l}49.4 \% \\
51.9 \% \\
28.1 \%\end{array}$ & $\begin{array}{l}31.6 \% \\
14.6 \% \\
13.8 \%\end{array}$ \\
\hline $\begin{array}{l}\text { Positive } \\
\text { Predictive } \\
\text { Value }\end{array}$ & $\begin{array}{l}\text { DAS28 } \\
\text { CDAl } \\
\text { RAPID3 }\end{array}$ & $\begin{array}{l}52.7 \% \\
55.1 \% \\
43.5 \%\end{array}$ & $\begin{array}{l}42.9 \% \\
44.1 \% \\
37.0 \%\end{array}$ & $\begin{array}{l}39.2 \% \\
35.4 \% \\
34.9 \%\end{array}$ \\
\hline $\begin{array}{l}\text { Negative } \\
\text { Predictive } \\
\text { Value }\end{array}$ & $\begin{array}{l}\text { DAS28 } \\
\text { CDAl } \\
\text { RAPID3 }\end{array}$ & $\begin{array}{l}70.9 \% \\
73.5 \% \\
75.0 \%\end{array}$ & $\begin{array}{l}80.6 \% \\
81.3 \% \\
78.7 \%\end{array}$ & $\begin{array}{l}84.4 \% \\
82.8 \% \\
79.1 \%\end{array}$ \\
\hline Accuracy & $\begin{array}{l}\text { DAS28 } \\
\text { CDAl } \\
\text { RAPID3 }\end{array}$ & $\begin{array}{l}67.7 \% \\
69.1 \% \\
60.9 \%\end{array}$ & $\begin{array}{l}58.3 \% \\
60.0 \% \\
47.0 \%\end{array}$ & $\begin{array}{l}50.5 \% \\
41.0 \% \\
40.0 \%\end{array}$ \\
\hline
\end{tabular}

Conclusions: Most patients with high/moderate disease activity did not have a MTC. This observation was consistent regardless of which DAM was utilised. MTC increased with disease activity with all DAMs; however, DAS28 and CDAI appeared to have greater accuracy than RAPID3 at predicting MTC at all disease severity thresholds. There is need for continued evaluation of DAM thresholds for defining disease activity for MTC decisions, better DAMs, and/or better application of DAMs in clinical practice to improve the treatment of patients with active RA.

Acknowledgements: This study was sponsored by Immunex, a subsidiary of Amgen. Medical writing assistance provided by Amgen.

Disclosure of Interest: G. Cannon Grant/research support from: Amgen, C.-C. Teng Grant/research support from: Amgen, N. Accortt Shareholder of: Amgen, Employee of: Amgen, D. Collier Shareholder of: Amgen, Employee of: Amgen, T.C. Lin Shareholder of: Amgen, Employee of: Amgen, B. Sauer Grant/research support from: Amgen Inc.

DOI: 10.1136/annrheumdis-2018-eular.1804

\section{FRI0019 ARE DISEASE ACTIVITY, DISABILITY OR PSYCHOLOGICAL FACTORS MOST ASSOCIATED WITH PATIENTS WITH RHEUMATOID ARTHRITIS BEING SATISFIED WITH THEIR CONDITION AFTER 12 MONTHS FOLLOWING TREATMENT ONSET?}

J. Gwinnutt ${ }^{1}$, K. Hyrich ${ }^{1,2}$, M. Lunt ${ }^{1}$, A. Barton ${ }^{2,3}$, S. Verstappen ${ }^{1,2}$, on behalf of RAMS coinvestigators. ${ }^{1}$ Arthritis Research UK Centre for Epidemiology, The University of Manchester, ${ }^{2}$ NIHR Manchester Biomedical Research Centre, Manchester University Hospitals NHS Foundation Trust, ${ }^{3}$ Arthritis Research UK Centre for Genetics and Genomics, The University of Manchester, Manchester, UK

Background: An important treatment goal in the management of patients with rheumatoid arthritis (RA) is patients being satisfied with their condition, the patient acceptable symptom state (PASS). It is unclear whether reduction in disease activity, the main therapeutic aim of RA treatment, is associated with reaching PASS, or whether reductions in other factors are also important.
Objectives: To analyse change over one year of disease activity, patient reported outcomes (PROs) and psychological factors and their association with PASS at one year.

Methods: The Rheumatoid Arthritis Medication Study (RAMS) is a prospective cohort of patients with RA starting MTX for the first time in the United Kingdom. At baseline and one year, patients reported demographics and completed pain and fatigue visual analogue scales (VAS-pain/VAS-fatigue), the Hospital Anxiety and Depression Scale (HADS-A, HADS-D) and the Health Assessment Questionnaire (HAQ). A research nurse performed a 28 swollen and tender joint count (SJC28/ TJC28) and the disease activity score (DAS28) was calculated. Patients answered the question "Is your current condition satisfactory, when you take your general functioning and your current pain into consideration?" at baseline and a one year. Only patients not in PASS at baseline are included in this analysis. Change in disease related factors (SJC28, TJC28, DAS28), PROs (HAQ, VASpain, VAS-fatigue), and psychological factors (HADS-A, HADS-D) from baseline to one year were calculated (see table 1). Predictors of PASS at one year were assessed using multivariable logistic regression, adjusting for age and gender The discriminative power of disease activity, PROs and psychological factors were assessed by comparing the area under the curve (AUC) of the receiver operating characteristic curve.

Results: Of 358 not in PASS at baseline (mean (SD) age: 58.1 (13.0) years; 244 (68.2\%) women), 241 (67.3\%) were in PASS after one year. The only independent predictors of PASS were change in HAQ, VAS-pain and HADS-D (OR $(95 \% \mathrm{Cl})$ per unit change from baseline: HAQ $0.38(0.16,0.91)$; VAS-pain $0.96(0.95,0.98)$; HADS-D $0.86(0.75,0.99))$. The model containing PROs had significantly greate AUC compared to a disease activity model $(0.91$ vs. $0.84, p=0.004)$ and a psychological factors model (0.91 vs. $0.81, \mathrm{p}<0.0001)$

Abstract FRI0019 - Table 1. Baseline, one year and change scores stratified by whether patients were in PASS at one year

\begin{tabular}{|c|c|c|c|c|c|c|}
\hline \multirow{2}{*}{ Variable } & \multicolumn{2}{|c|}{ Median (IQR) baseline score } & \multicolumn{2}{|c|}{ Median (IQR) one year score } & \multirow{2}{*}{\multicolumn{2}{|c|}{$\begin{array}{c}\text { Median (IQR) Change } \\
\text { PASS at one Not-PASS at one }\end{array}$}} \\
\hline & PASS at one & Not-PASS at one & PASS at one & Not-PASS at one & & \\
\hline Disease activity & & & & & & \\
\hline & $6.5(2.5,11.0)$ & $6.0(3.0,12.0)$ & $0.0(0.0,2.0)$ & $3.0(0.0,7.0) \ddagger$ & $-5(-9,-2)$ & $-2(-6,1) \neq$ \\
\hline TJC28 & $6.0(3.0,12.0)$ & $9.0(5.0,17.0)^{+}$ & $1.0(0.0,4.0)$ & $8.0(2.0,14.0) \neq$ & $-4(-9,-1)$ & \\
\hline DAS28 & $4.6(3.8,5.4)$ & $4.9(4.2,5.8)$ & $2.7(2.1,3.5)$ & $4.3(3.5,5.3) \neq$ & $-1.6(-2.9,-0.8)$ & $-0.6(-1.6,0.4)$ \\
\hline$H A Q$ & $1.3(0.8,1.8)$ & $1.4(1.0,1.9)$ & $0.6(0.1,1.1)$ & $1.5(1.0,1.9) \neq$ & $-0.5(-1.0,-0.1)$ & $0.0(-0.4,0.3) \neq$ \\
\hline VAS-Pain & $63(46,75)$ & $68(50,80)$ & $18(7,33)$ & $60(41,76) \neq$ & $-38(-55,-18)$ & $-5(-24,9) \neq$ \\
\hline $\begin{array}{l}\text { VAS-Fatigue } \\
\text { psychol }\end{array}$ & $62(37,74)$ & $72(57,85) \neq$ & $29(13,54)$ & $70(55,83) \div$ & $-24(-43,-1)$ & $-1(-17,12) \neq$ \\
\hline $\begin{array}{l}\text { Psychological } \\
\text { HADS-D }\end{array}$ & $7(4,10)$ & $8(5,10)$ & $3(1.6)$ & $8(5,11) \neq$ & $-2(-5,0)$ & $1(-1,2) \neq$ \\
\hline HADS-A & $6(4,10)$ & $8(4,12) \pm$ & $4(2,8)$ & $8(4,11) \neq$ & $-2(-4,0)$ & $0(-2,2) \neq$ \\
\hline
\end{tabular}

Conclusions: Change in PROs have a greater association with attaining PASS at one year compared to disease related or psychological factors and should be taken into account when designing treatment strategies.

Disclosure of Interest: None declared

DOI: 10.1136/annrheumdis-2018-eular.5212

\section{FRI0020 ANTI-CEP-1 ANTIBODIES AND OTHER AUTOANTIBODIES IN EARLY ARTHRITIS}

M. Ponikowska ${ }^{1}$, J. Świerkot ${ }^{2}$, B. Nowak ${ }^{3}$, L. Korman ${ }^{2}$, P. Wiland ${ }^{2}{ }^{1}$ Department of Rheumatology and Internal Medicine, Wroclaw University Hospital; ${ }^{2}$ Department of Rheumatology and Internal Medicine; ${ }^{3}$ Department of Pharmacology, Wroclaw Medical University, Wroclaw, Poland

Background: As it is very important to identify patients with a high risk of developing rheumatoid arthritis (RA), new, diagnostic methods, evaluating the possibility of progression from undifferentiated arthritis (UA) to RA are needed.

Objectives: The aim of this work was the evaluation of the frequency of rheumatoid factor, anti-cyclic citrullinated peptide (anti-CCP) antibodies, mutated citrullinated vimentin antibodies (a-Sa), anti-CEP-1 antibodies, anti-filaggrin antibodies (AFA), heterogeneous nuclear ribonucleoprotein compies/anti-RA33-antibody (HnRNP/RA33), anti-CarP antibodies (a-Carp) in patients with early arthritis.

Methods: 74 patients with early arthritis and 20 healthy volunteers were enrolled to the study. 51 patients were diagnosed with RA, 23 with UA. Exclusion criteria were the application of disease-modifying antirheumatic drugs or glucocorticosteroids. In all patients the following laboratory tests were performed: inflammatory markers, rheumatoid factor (RF) and antibodies mentioned above, together with necessary diagnostic that enables diagnosis.

Results: In patients with early arthritis the sensitivity and specificity of the presence of RF was $69 \%$ and $95 \%$, respectively, and of anti-CCP was $67 \%$ and $97 \%$.

In patients with early arthritis we observed significantly higher concentration of CEP-1 $(65,8 \pm 111,6)$ than in the healthy group $(2,0 \pm 0,0)$. In $R F(+) R A$ patients we 